\title{
Assessment of Coagulation Disorder in Women Taking Oral Contraceptives
}

\author{
Samsunnahar', Qazi Shamima Akhter ${ }^{2}$ Atiquzzaman $^{3}$, Najneen Akhter ${ }^{4}$, \\ Umme Sultana Naima Begum ${ }^{5}$, Farhana Rahman 6
}

\begin{abstract}
Background: Oral contraceptive pill (OCP) is related to development of hypercoagulability and the risk of thromboembolic effects in women. Objectives: To assess the coagulability status in women taking oral contraceptives by estimation of plasma fibrinogen level and total count of platelets. Methods: This cross sectional study was conducted in the Department of Physiology, Dhaka Medical College, Dhaka, during the period of January 2012 to December 2012 on sixty apparently healthy female subjects aged 25 to 45 years taking $\mathrm{OCP}_{-\mathrm{s}}$ for 1 to 10 years. Thirty subjects were 1 to 5 years user group and another 30 subjects were $>5$ to 10 years user group. They were collected from family planning clinics of Dhaka city. In addition, age matched 30 apparently healthy women of OCP nonusers were also studied as control. For assessment of coagulability state, plasma fibrinogen and total counts of platelet levels were estimated by automated coagulation analyzer and automated hematology analyzer. Statistical analysis was done by unpaired Student's t' test. Results: The mean $( \pm \mathrm{SE})$ total count of platelet level was significantly higher $(\mathrm{P}<0.001)$ in contraceptive user group and plasma fibrinogen level was higher in users but it was not significant. Conclusion: This study concludes that OCP users had more tendency of hypercoagulability and therefore these women are at higher risk of thromboembolic effects.
\end{abstract}

Key words: Oral Contraceptives, Hypercoagulability, Plasma fibrinogen, Total counts of platelet, Thromboembolism.

Bangladesh Soc Physiol. 2014, June; 9(1): 1-5 For Authors Affiliation, see end of text.

http://www.banglajol.info/index.php/JBSP

\section{Introduction}

7 he combined formulation of estrogen and progestins are widely used as a temporary contraceptives; however their safe use has been remained under debate ${ }^{1}$. Combined hormonal oral contraceptives containing less than $50 \mu \mathrm{g}$ ethinyl estradiol has been named as low dose oral contraceptives ${ }^{2}$. Despite the general acceptability and the obvious advantages that have been attributed to low dose oral contraceptive use, some serious side effects

Received March 2014;

Accepted June 2014

J Bangladesh Soc Physiol. 2014, June; 9(1): 1-5 have been reported in women taking the pills. Epidemiologic studies were found a relationship between oral contraceptive use and altered level of coagulation factors, platelet changes and thromboembolic phenomenon ${ }^{3}$.

OCP users developed a state of hypercoagulability that was indicated by the significant elevation of plasma fibrinogen level, factor XII, vitamin $\mathrm{K}$ dependent clotting factors and total count of platelets which can lead to thromboembolic episodes ${ }^{4,5,6}$. 
Women, who were taking OCPs, had an elevation of factor VII\& fibrinogen levels. In men, the risk of ischemic heart disease is strongly related to the elevated levels of factor VII \& fibrinogen. Thus it is suggested that there is an association with the elevated levels of fibrinogen, factor VII and risk of ischemic heart disease in women taking oral contraceptives ${ }^{7}$.

Higher level of blood coagulation factors and activated protein $\mathrm{C}$ resistance were the causative factors for the risk of development of venous thromboembolism in women taking $\mathrm{OCP}_{-\mathrm{s}}{ }^{8,9}$.

Though most of the results showed higher total count of platelet and fibrinogen in user group $3,4,10$ but some researchers found no change in these parameters ${ }^{5,11.12}$. Therefore because of this conflicting results this study has been designed to estimate fibrinogen level and total counts of platelet to observe the coagulability of OCP users with different duration. Early preventive measure $\&$ treatment of it can reverse or reduce the risk of developing thromboembolism. This study will also help to build awareness about thromboembolism which is now highly focused topic of reproductive health. Moreover early detection \& prevention of it can reduce morbidity $\&$ mortality and thus reduce burden on our health budget.

\section{Methods}

This cross sectional study was carried out in the Department of Physiology, Dhaka Medical College, Dhaka between January 2012 and December 2012. The protocol of this study was approved by the Ethical Review Committee of Dhaka Medical College, Dhaka. Sixty apparently healthy women aged 25 to 45 years using hormonal oral contraceptives (Shukhi containing $30 \mu \mathrm{g}$ of ethinyl estradiol and $150 \mu \mathrm{g}$ of levonorgestrel) for 1 to 10 years were selected from family planning clinics of Nari Maitree \& from personal contact in different area of Dhaka city. They were divided in two groups according to duration of contraceptive use. Thirty women with 1 to 5 years and 30 women include between 5 to 10 years user group. Subjects were excluded with history of heart, liver, and kidney diseases. They were also excluded from any endocrine disease, hormone replacement therapy, steroid, aspirin and anti-platelet aggregator users. The aim, objective and benefit of this study was explained to all subjects with a careful and friendly attitude. If they agree then a written informed consent was collected from them. Then a thorough clinical examination of all subjects were done. All information were recorded in a data sheet. Then under aseptic precautions $5 \mathrm{ml}$ venous blood was drawn and transferred into 2 separate test tubes containing $3.8 \%$ trisodium citrate and EDTA respectively. Immediately the samples were send to the immunology and hematology laboratory of BIRDEM, shahbag Dhaka. Plasma fibrinogen level was analyzed on automated coagulation analyzer, Sysmex CA 500 series by using the Dade ${ }^{\circledR}$ Fibrinogen determination reagent and total count of platelet was analyzed on Sysmex Automated Hematology Analyzer, XT- 1800 I. Data were expressed as mean $( \pm \mathrm{SE})$. Comparison of data between users and nonusers as well as between different duration of use were compared by Unpaired Student' $s$ ' $t$ ' test for statistical analysis. Data was evaluated using SPSS version 12.

\section{Results}

The mean $( \pm \mathrm{SE})$ total count of platelet level in OCP users were significantly higher than that of nonusers (Table I). There was no significant difference in this parameter when compared between different duration of OCP use. (Table II)

The mean $( \pm$ SE) plasma fibrinogen level in OCP users were higher than that of nonusers but the results were not statistically significant (Table I). There was no significant difference in this parameter when compared between different duration of OCP use. (Table II).

J Bangladesh Soc Physiol. 2014, June; 9(1): 1-5 
Table 1 : Plasma fibrinogen and total count of platelet levels in different groups $(n=90)$

\begin{tabular}{lcc}
\hline Parameter & $\begin{array}{c}\text { OCP nonuser } \\
(\mathrm{n}=30)\end{array}$ & $\begin{array}{c}\text { OCP user } \\
(\mathrm{n}=60)\end{array}$ \\
\hline Plasma fibrinogen & $266.57 \pm 7.99$ & $277.17 \pm 6.07$ \\
$(\mathrm{mg} / \mathrm{dl})$ & $(214.00-385.00)$ & $(206.00-402.00)$ \\
Total count of platelet & $272.57 \pm 6.66$ & $319.20 \pm 7.09 * *$ \\
$\left(\mathrm{x} 10^{3} / \mu \mathrm{L}\right)$ & $(190.00-360.00)$ & $(206.00-406.00)$ \\
\hline
\end{tabular}

Data expressed as mean $( \pm \mathrm{SE})$. Figures in parentheses indicate range. Unpaired Student's ' $t$ ' test was performed to compare between OCP nonuser and users.** $(\mathrm{p}<0.01)$

Table II : Plasma fibrinogen and total count of platelet levels in different duration of OCP use $(n=60)$

\begin{tabular}{lcc}
\hline Parameter & $\begin{array}{c}\text { OCP user }(1-5 \text { yrs }) \\
(\mathrm{n}=30)\end{array}$ & $\begin{array}{c}\text { OCP user }(>5-10 \text { yrs }) \\
(\mathrm{n}=30)\end{array}$ \\
\hline Plasma fibrinogen & $265.87 \pm 7.49$ & $288.47 \pm 9.24$ \\
$(\mathrm{mg} / \mathrm{dl})$ & $(208.00-386.00)$ & $(206.00-402.00)$ \\
Total count of platelet & $316.57 \pm 11.29$ & $319.20 \pm 7.09$ \\
$\left(\mathrm{x} 10^{3} / \mu \mathrm{L}\right)$ & $(206.00-406.00)$ & $(254.00-390.00)$ \\
\hline
\end{tabular}

Data expressed as mean $( \pm \mathrm{SE})$. Figures in parentheses indicate range.

\section{Discussion}

In the present study, total counts of platelet and plasma fibrinogen levels in OCP users were almost within normal range. But the levels were higher in OCP users than nonusers and almost similar to the published reports of different researches of different countries $3,4,10,11,12$.

In this study, plasma fibrinogen level in women of OCP users was higher than that of nonusers. But the result was not statistically significant. This finding was in agreement with the study of different researchers of different countries ${ }^{11,12}$. On the contrary, similar types of studies by other workers found higher plasma fibrinogen level in OCP users than nonusers, which was statistically significant $^{3,4,10}$. Again, In the present study, the mean value of total counts of platelet in women of OCP users were higher than that of nonusers and the result was statistically highly

J Bangladesh Soc Physiol. 2014, June; 9(1): 1-5 significant. Similar observations were made by other workers ${ }^{3,4,10}$. On the other hand, mean value of total counts of platelet were remain unchanged in between OCP users \& control subjects which was also observed by some investigators ${ }^{5}$. This inconsistence of the results may be due to small sample size in their study.

Many explanations are suggested by different investigators for the increased levels of total count of platelet and plasma fibrinogen in oral contraceptive users than nonusers but the exact mechanism is not yet clear. There may be due to presence of estrogen in combined oral contraceptive pills that acts as a contributory factor for the significant elevation of the plasma fibrinogen level \& total counts of platelet. These might play an important role in development of hypercoagulability and thromboembolism. Such changes introduce a risk of superficial and deep 
venous thrombosis, pulmonary embolism and cerebral arterial thrombosis ${ }^{2,4}$.

Clinical \& epidemiological studies indicate that use of OCP is associated with an increased risk of thrombotic disorders ${ }^{13}$. Some researchers suggested that plasma concentration of several markers of coagulation (clotting factors of intrinsic and extrinsic blood coagulation) had been found higher in users compared with nonusers of oral contraceptives. These elevated levels of coagulation factors were thought to be a primary factor that increased thrombotic risk in OCP users ${ }^{10}$. Another studies showed that women taking hormonal oral contraceptives had increased level of blood clotting factors. This increased level was associated with the decreased level of anticoagulant proteins such as antithrombin and protein S. It had been observed that women taking hormonal oral contraceptives developed activated protein $\mathrm{C}$ resistance, which might provide an explanation for the increased thrombotic risk ${ }^{14}$. It had been reported that there was an age dependent increased in the prevalence of the risk of cerebral thromboembolism in women using oral contraceptives. It was more common in women of higher age group ${ }^{15}$. Another study showed increased lipid profile in women who were taking OCP-s-. Thus it was possible that the elevated lipid profile in OCP users provides a surface upon which Prothrombin complexes were activated and hypercoagulability was produced. As a result, thromboembolic effect was developed in OCP users than nonusers ${ }^{16}$.

In the present cross sectional study, significantly higher level of total counts of platelet and nonsignificant increase in plasma fibrinogen levesl in OCP users than nonusers are most likely due to higher level of blood clotting factors caused by the estrogen content of the pill and the wider age range of the study subjects. However, the reason for non-significant increase in plasma fibrinogen level among OCP users than nonusers as well as between users of different durations may be due to smaller sample size of the present study.

\section{Conclusion}

From this study, it can be concluded that the probability of development of hypercoagulable state \&increased risk of thromboembolism are more in OCP users. Significantly higher levels of total count of platelet and plasma fibrinogen are found in women of oral pill users. It could be used as a screening test along with other biomarker. So, a further study on this field is required for clarification.

\section{Acknowledgement}

The Authors of this study are thankful to the study subjects for their active, sincere and voluntary participation.

\section{Author affiliations}

1. *Samsunnahar, Assistant Professor, Department of Physiology, Holy Family Red Crescent Medical College, Dhaka. Email: bina.nahar@yahoo.com

2. Qazi Shamima Akhter, Professor \& Head, Department of Physiology, Dhaka Medical College, Dhaka. Email: shamimaqazi@yahoo.com

3. Atiquzzaman, Resident, Department of Physical Medicine \& Rehabilitation, BSMMU, Dhaka. Email: binduatiq@yahoo.com

4. Najneen Akhter, Associate Professor, Department of Physiology, Holy Family Red Crescent Medical College, Dhaka. Email:akhter.najneen@yahoo.com

5. U.S. Naima Begum, Professor \& Head, Department of Physiology, Holy Family Red Crescent Medical College, Dhaka. Email:naimabegum50@yahoo.com

6. Farhana Rahman, Assistant Professor, Department of Physiology, Delta Medical College, Dhaka. Email: rahman_farhana82@yahoo.com

\section{References}

1. Afsar NA, Barakzai Q, Adil SN. Effects of low dose oral pill on haemostatic parameters in a set of Pakistani population. J Pa Med A. 2008; 58 :229231.

2. Kumar P \& Malhotra N. eds. Jeffcoate's principles of gynaecology. $7^{\text {th }}$ ed.New Delhi: Jaypee; 2008. p.676-678.

3. Babatunde A, Olatunji P. Short-term effect of oral contraceptive pills on some haemostatic parameters in healthy Nigerian women. Niger Post Grad Med J. 2004; 4: 246-250.

J Bangladesh Soc Physiol. 2014, June; 9(1): 1-5 
4. Abdalla TM, Kordofani AAY, Nimir AAH. Haemostatic studies in Sudanese women on oralcontraceptive pills. Khartoum Medical Journal. 2008; 3: 116-118

5. Notelovitz M, Kitchens CS, Khan FY. Changes in coagulation and anticoagulation in women taking low-dose triphasic oral contraceptives: a controlled comparative 12- month clinical trial. Am J Obstet Gynecol. 1992; 167:1255-61.

6. Kelleher CC. Clinical aspects of the relationship between oral contraceptives and abnormalities of the haemostatic system: relation to the development of cardiovascular disease. Am J Obstet Gynecol. 1990; 163 :392-5.

7. Bhatla N. ed. Jeffcoate's principles of Gynaecology. $6^{\text {th }}$ ed. New Delhi: Arnold; 2001. p.678.

8. Ramirez ML, Azcona CM, Sanchez JMR,Maties MQ, Morreale HFE. Effects of an antiandrogenic oral contraceptive pill compared with metformin on blood coagulation tests and endothelial function in women with the polycystic ovary syndrome: influence of obesity and smoking. European Journal of Endocrinology.2009; 160: 469-480.

9. Bottiger LE, Boman G, Eklund G \& Westerholm B. Oral contraceptive and thromboembolic disease: effects of lowering estrogen content. Lancet. 1980; 1097-1101.

10. AL-Husaynee AJ, Kashmoola MA 2007. Effects of combined oral contraceptive pills on some haemostatic parameters. Ann. Coll. Med. Mosul. 2007; 33 (1\& 2): 66-69.

11. Roudsari HRS, Faghini M, Karimian SM. Effects of oral contraceptives on coagulation factors. Acta Medica Iranica. 1997; 35(1): 26-28.

12. Alkjaersig N, Fletcher A, Burstein R. Association between oral contraceptive use \& thromboembolism: a new approach to its investigation based on plasma fibrinogen chromatography. Am J Obstet Gynecol.1975; 122 (2): 199-209.

13. VandenbrouckeJP, Rosing J, Bloemerkamp KWM, Middeldorp S, Helmerhorst FM, Bouma BN, Rosendaal FR. Oral contraceptives and the risk of venous thrombosis. N Engl J Med.2001; 344: 15271535 .

14. Thacker HL. Hormone therapy and risk of venous thromboembolism. [Internet]. 2010. Available from: www.clevelandclinicmeded.com/medical pubs/ disease managem.

15. Lidegaard O. Oral contraception and risk of a cerebral thromboembolic attack: results of a casecontrol study. Brit Med J.1993; 306: 956-63.

16. Schrogie JJ, Solomon HM \& Zieve PD. Effects of oral contraceptives on vitamin K-dependent clotting activity. Clinical Pharmacology and Therapeutics. 1967; 8(5): 670-675. 